\title{
High-temperature ceramic oxide superconductors ${ }^{+}$
}

\author{
C N R RAO \\ Solid State and Structural Chemistry Unit, Indian Institute of Science, \\ Bangalore 560012 , India
}

\begin{abstract}
High-temperature superconductivity in oxides of the type $\mathrm{La}_{2-x} \mathrm{Ba}_{x}\left(\mathrm{Sr}_{x}\right) \mathrm{CuO}_{4}, \mathrm{YBa}_{2} \mathrm{Cu}_{3} \mathrm{O}_{7-\delta}, \mathrm{La}_{3-x} \mathrm{Ba}_{3+x} \mathrm{Cu}_{6} \mathrm{O}_{14}$ and $\mathrm{Bi}(\mathrm{Tl})-$ $\mathrm{Ca}-\mathrm{Sr}(\mathrm{Ba})-\mathrm{Cu}-\mathrm{O}$ systems is discussed, with special emphasis on the experimental findings from the author's laboratory. The importance of holes on oxygen and of the $\mathrm{Cu}^{1+}\left(d^{10}\right)$ state is examined. A transition is shown to occur from chain- to sheet-superconductivity in $\mathrm{YBa}_{2} \mathrm{Cu}_{3} \mathrm{O}_{7-\delta}$ accompanying a change in oxygen stoichiometry. Some of the important material parameters and technological applications are briefly presented. There is every hope that materials with $T_{c}$ close to room temperature will be discovered in the near future. All the high $T_{c}$ oxides found hitherto have perovskite-related structures with two-dimensional $\mathrm{Cu}-\mathrm{O}$ sheets.
\end{abstract}

Keywords. High-temperature superconductivity; ceramic oxide superconductors; bismuth cuprates; thallium cuprates; $\mathrm{LnBa}_{2} \mathrm{Cu}_{3} \mathrm{O}_{7}$; rare earth cuprates.

\section{Introduction}

The phenomenon of superconductivity has been an area of vital interest for the past several decades, ever since Kammerlingh Onnes discovered in 1911 that mercury becomes superconducting at $4.2 \mathrm{~K}$. Many materials, mostly metals and alloys, and more recently, molecular systems including organic charge-transfer compounds, have been investigated for superconductivity, but the superconducting transition temperature did not cross $23 \mathrm{~K}$ till 1986 . The average rate of increase in $T_{c}$ was about 3 degrees per decade and it appeared as though $23 \mathrm{~K}$ was the upper limit for the $T_{c}$. The highest $T_{c}$ 's (in the $20 \mathrm{~K}$ region) were exhibited by the A15 compounds such as $\mathrm{Nb}_{3} \mathrm{Sn}$ and $\mathrm{Nb}_{3} \mathrm{Ge}$. Some of the metal oxides also showed superconductivity, the highest $T_{c}$ amongst them being exhibited by $\mathrm{Ba} \mathrm{Pb}_{1-x} \mathrm{Bi}_{x} \mathrm{O}_{3}$ and $\mathrm{LiTi}_{2} \mathrm{O}_{4}$, both around $13 \mathrm{~K}$.

Bednorz \& Mueller (1986) showed the possibility of high-temperature superconductivity in oxides of the La-Ba-Cu-O system. It was established in January 1987 that these oxides had the general formula $\mathrm{La}_{2}-x \mathrm{Sr}_{x}\left(\mathrm{Ba}_{x}\right) \mathrm{CuO}_{4}$ and possessed the $\mathrm{K}_{2} \mathrm{NiF}_{4}$ structure; $T_{c}$ values in these oxides were in the $20-40 \mathrm{~K}$ region, the compositions corresponding to the maximum $T_{c}$ in the $\mathrm{Sr}$ and $\mathrm{Ba}$ systems being $x=0.2$ and 0.15 , respectively (Cava et al 1987; Chu et al 1987; Ganguly et al 1987a;

${ }^{+}$Contribution No. 485 from the Solid State and Structural Chemistry Unit. 
Uchida et al 1987). Following on the heels of this discovery, superconductivity above liquid nitrogen temperature was reported in March 1987 in the $\mathrm{Y}-\mathrm{Ba}-\mathrm{Cu}-\mathrm{O}$ system (Wu et al 1987). It was soon found that the oxide responsible for superconductivity in this system did not possess the $\mathrm{K}_{2} \mathrm{NiF}_{4}$ structure, but instead had the defect perovskite structure with the composition $\mathrm{YBa}_{2} \mathrm{Cu}_{3} \mathrm{O}_{7-\delta}$ (Ganguly et al $1987 \mathrm{~b}$; Rao et al 1987b; Siegrist et al 1987). In the last few weeks, the big news has been the discovery of superconductivity in $\mathrm{Bi}$ and $\mathrm{Tl}$ cuprates containing alkaline earth metals; these oxides show $T_{c}$ 's in the 100-120 K range (Chu et al 1988; Ganguli et al 1988; Rao et al 1988; Subramanian et al 1988; Sheng \& Hermann 1988).

The discovery of superconductivity above the liquid nitrogen temperature in oxide materials has raised much hope because of its important technological implications. Equally importantly, this has given a big boost to research in ceramic oxides. In what follows, some of the highlights of research on high $T_{c}$ oxide superconductors will be presented, with particular reference to the results obtained in the author's laboratory (Rao 1988). In addition, some of the special features of these ceramic oxides will be indicated along with their possible technological applications. It may be remarked here that research efforts in this laboratory related to the hightemperature superconducting oxides were initiated in the early part of January 1987, soon after information about the $\mathrm{La}_{2-x} \mathrm{Ba}_{x}\left(\mathrm{Sr}_{x}\right) \mathrm{CuO}_{4}$ system became available through the American participants in the International Conference on Valence Fluctuation held in Bangalore.

\section{2. $\mathrm{La}_{2-x} \mathrm{Ba}_{x}\left(\mathrm{Sr}_{x}\right) \mathrm{CuO}_{4}$}

Oxides of the general formula $\mathrm{A}_{2} \mathrm{BO}_{4}$ possess the quasi two-dimensional $\mathrm{K}_{2} \mathrm{NiF}_{4}$ structure (figure 1) wherein the $\mathrm{B}$ ions interact only in the $a b$ plane. The structure and properties of the oxides of the $\mathrm{K}_{2} \mathrm{NiF}_{4}$ system have been examined in some detail recently by Ganguly \& Rao (1984). It has been known for sometime that orthorhombic $\mathrm{La}_{2} \mathrm{CuO}_{4}$ is a relatively low-resistivity material ( $\sim 1 \mathrm{ohm} \mathrm{cm}$ at $300 \mathrm{~K}$, see figure 2) and becomes antiferromagnetic at low temperatures. Substitution of $\mathrm{La}$ by $\mathrm{Ba}$ or $\mathrm{Sr}$ in $\mathrm{La}_{2-x} \mathrm{Ba}_{x}\left(\mathrm{Sr}_{x}\right) \mathrm{CuO}_{4}(x>0.05)$ makes the structure tetragonal (at room temperature) and superconductivity manifests itself at low temperatures (Rao \& Ganguly 1987a). Superconductivity is also found in the $15-40 \mathrm{~K}$ region in oxides of the type $\left(\mathrm{La}_{1-y} \mathrm{Ln}_{y}\right)_{2-x} \mathrm{Ba}_{x}\left(\mathrm{Sr}_{x}\right) \mathrm{CuO}_{4}$ where $\mathrm{Ln}=\mathrm{Pr}, \mathrm{Nd}, \mathrm{Gd}$ etc. (Ganguly et al 1987a; Mohan Ram et al 1987a). These oxides, containing planar $\mathrm{CuO}_{2}$ units, show maximum $T_{c}$ around a specific value of $x$ (Sreedhar et al 1987). Electrical resistivity values of these oxides in the normal state above $T_{c}$ are in the $10^{-2}-10^{-3} \mathrm{ohm} . \mathrm{cm}$ range (figure 2) which correspond closely to Mott's minimum metallic conductivity (Rao \& Ganguly 1985).

There have been several investigations of $\mathrm{La}_{2} \mathrm{CuO}_{4}$ and $\mathrm{La}_{2-x} \mathrm{Ba}_{x}\left(\mathrm{Sr}_{x}\right) \mathrm{CuO}_{4}$ in the last few months. Antiferromagnetism in $\mathrm{La}_{2} \mathrm{CuO}_{4}$ has been established by neutron scattering and diffraction studies, the $T_{N}$ being close to $290 \mathrm{~K}$ with a lowtemperature Cu-moment of $0.43 \mu_{B}$ (Mitsuda et al 1987). Besides establishing the magnetic structure, these studies have shown the occurrence of the orthorhombictetragonal distortion at $505 \mathrm{~K}$. Muon spin rotation has also been employed to examine antiferromagnetism in $\mathrm{La}_{2} \mathrm{CuO}_{4}$ (Uemura et al 1987). The work of Shirane et al (1987) has shown that $\mathrm{La}_{2} \mathrm{CuO}_{4}$ is in a 2-dimensional afm quantum fluid state wherein spins are ordered instantaneously over long distances, but there is no 


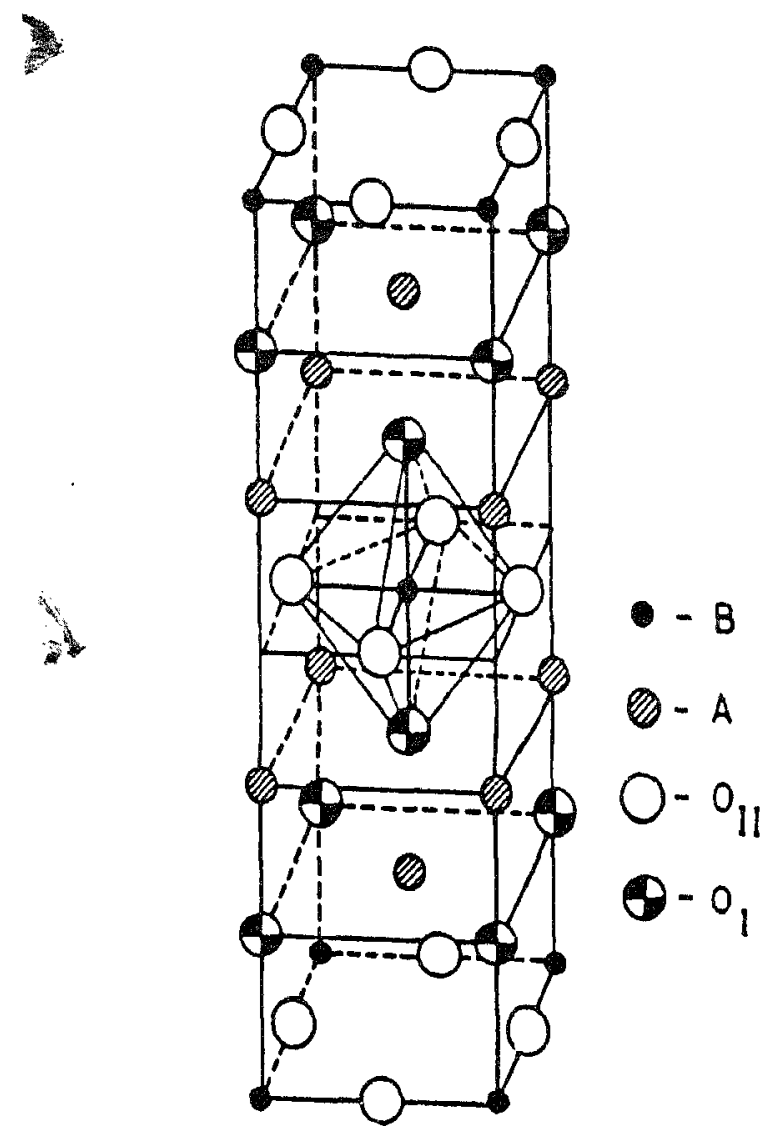

Figure 1. The $\mathrm{K}_{2} \mathrm{NiF}_{4}$ structure of oxides of the formula $\mathrm{A}_{2} \mathrm{BO}_{4}$.

measurable time-averaged moment. More interestingly, studies of oxygen-excess $\mathrm{La}_{2} \mathrm{CuO}_{4}$ has shown it to be superconducting with a $T_{c}$ of $40 \mathrm{~K}$ (Beille et al 1987); La-deficient samples also exhibit superconductivity in this temperature region.

Superconducting $\mathrm{La}_{2-x} \mathrm{Ba}_{x}\left(\mathrm{Sr}_{x}\right) \mathrm{CuO}_{4}$ undergoes a tetragonal-orthorhombic distortion around $180 \mathrm{~K}$ (Day et al 1987; Paul et al 1987). ESR studies have thrown light on microscopic magnetic interactions in these oxides (Thomann et al 1987). Static and dynamic aspects of the tetragonal-orthorhombic distortion in $\mathrm{La}_{2-x} \mathrm{Sr}_{x} \mathrm{CuO}_{4}$ have been studied by neutron scattering and related studies and a classical soft phonon behaviour involving $\mathrm{CuO}_{6}$ octahedra has been observed (Birgeneau et al 1987).

\section{3. $\mathrm{YBa}_{2} \mathrm{Cu}_{3} \mathrm{O}_{7-\delta}$ and related oxides}

Wu et al (1987) reported superconductivity above liquid $\mathrm{N}_{2}$ temperature in $\mathrm{Y}_{1.2} \mathrm{Ba}_{0.8} \mathrm{CuO}_{4}$. This composition was actually biphasic, consisting of green $\mathrm{Y}_{2} \mathrm{BaCuO}_{5}$ and a black oxide. We had initiated studies (Ganguly et al 1987b) on the $\mathrm{Y}-\mathrm{Ba}-\mathrm{Cu}-\mathrm{O}$ system with compositions of the type $\mathrm{Y}_{3-x} \mathrm{Ba}_{3+x} \mathrm{Cu}_{6} \mathrm{O}_{14-\delta}$ by analogy with $\mathrm{La}_{3-x} \mathrm{Ba}_{3+x} \mathrm{Cu}_{6} \mathrm{O}_{14-\delta}$ (Er-Rakho et al 1981). This was because $\mathrm{Y}_{2} \mathrm{CuO}_{4}$ (unlike $\mathrm{La}_{2} \mathrm{CuO}_{4}$ ) does not crystallize in the $\mathrm{K}_{2} \mathrm{NiF}_{4}$ structure. By comparing the $\mathrm{X}$ ray diffraction patterns of $\mathrm{Y}_{3-x} \mathrm{Ba}_{3+x} \mathrm{Cu}_{6} \mathrm{O}_{14-\delta}$ and $\mathrm{Y}_{2} \mathrm{BaCuO}_{5}$, it was possible to identify the phase responsible for the high $T_{c}(90-95 \mathrm{~K})$ superconductivity as 


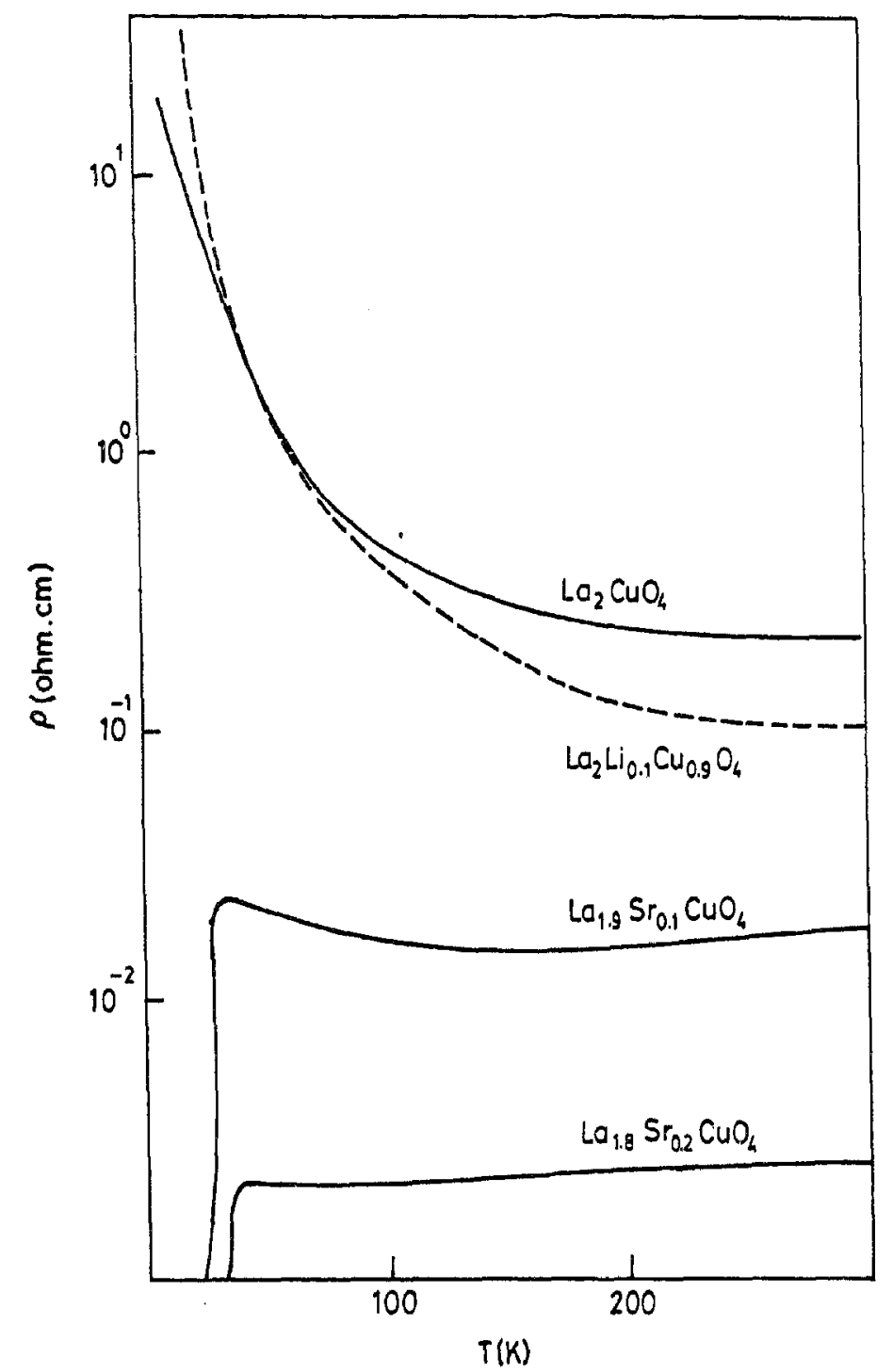

Figure 2. Electrical resistivity behaviour of $\mathrm{La}_{2}-\mathrm{Sr}_{x} \mathrm{CuO}_{4}$ and $\mathrm{La}_{2} \mathrm{CuO}_{4}$ (from Ganguly et al 1987a).

orthorhombic $\mathrm{YBa}_{2} \mathrm{Cu}_{3} \mathrm{O}_{7-\delta}$ ( $\mathrm{Rao}$ et al 1987b). AC susceptibility (Meissner effect) measurements showed the superconductivity to be a bulk property. Soon, many other related oxides such as $\mathrm{Y}_{1-x} \mathrm{Ln}_{x} \mathrm{Ba}_{2} \mathrm{Cu}_{3} \mathrm{O}_{7-\delta}(\mathrm{Ln}=\mathrm{La}$, Lu etc) as well as $\mathrm{LnBa}_{2} \mathrm{Cu}_{3} \mathrm{O}_{7-\delta}\left(\mathrm{Ln}=\mathrm{Er}, \mathrm{Dy}, \mathrm{Gd}\right.$ etc.) were found to be high $T_{\mathrm{c}}$ superconductors, all with $T_{c} \approx 90 \mathrm{~K}$ (Mohan Ram et al 1987b; Raychaudhuri et al 1987; Tarascon et al 1987; Xiao et al 1987). Obviously $\mathrm{Y}$ and $\mathrm{Ln}$ ions play no role in the superconductivity; they only help to keep the structure together.

Superconductivity in $\mathrm{YBa}_{2} \mathrm{Cu}_{3} \mathrm{O}_{7-\delta}$ is extremely sensitive to oxygen stoichiometry (Rao et al 1987a, 1988a; Rao \& Ganguly 1987b). Thus, the $\delta \geqslant 0.6$ sample is nonsuperconducting and tetragonal. Oxygen is readily intercalated into the $\delta \geqslant 0.5$ 


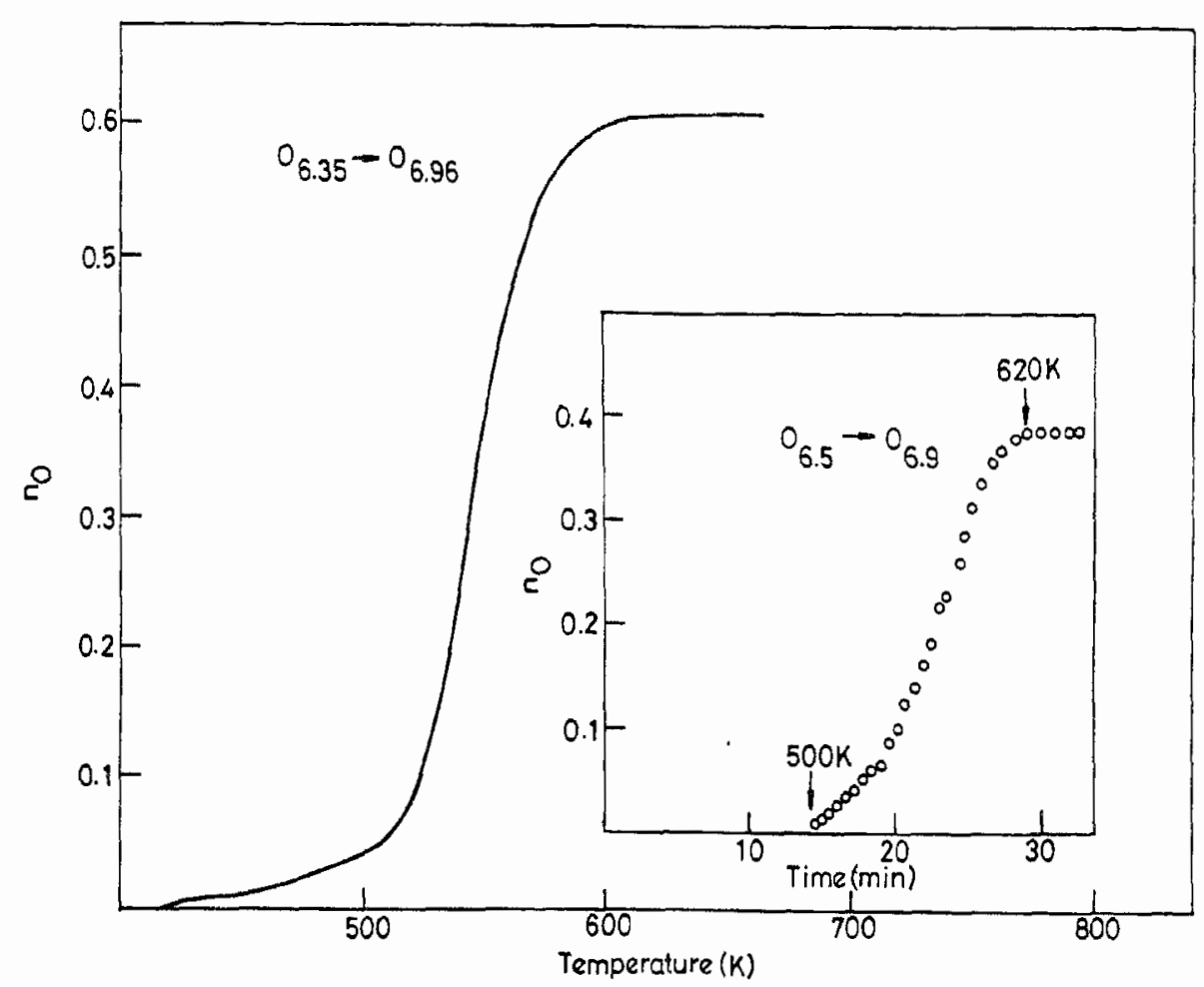

Figure 3. TGA curves showing the oxidation of $\mathrm{YBa}_{2} \mathrm{Cu}_{3} \mathrm{O}_{6.5}$ to $\mathrm{YBa}_{2} \mathrm{Cu}_{3} \mathrm{O}$. Inset shows the rate of oxygen intercalation in a $O_{6.5}$ sample (from Rao et al 1988a).

samples and the stoichiometry reaches close to $\mathrm{YBa}_{2} \mathrm{Cl}_{3} \mathrm{O}_{7}$ on intercalation (figure 3). Structures of the orthorhombic $(\delta=0.0)$ and the tetragonal $(\delta=1.0)$ phases differ in an interesting manner. Besides the $\mathrm{CuO}_{2}$ sheets, the stoichiometric $(\delta=0.0)$ phase contains $\mathrm{Cu}-\mathrm{O}-\mathrm{Cu}$ chains (or corner-linked $\mathrm{CuO}_{4}$ ) units which are absent in the nonsuperconducting $(\delta=1 \cdot 0)$ sample (David et al 1987; Bordet et al 1987). In figure 4 we compare the orthorhombic and tetragonal structures of the $\delta=0.0$ and the $\delta=1.0$ samples. In the $\delta=0.6-1.0$ range, it seems that the tetragonal phase has disordered oxygens giving rise to distorted $\mathrm{CuO}_{6}$ octahedra as indicated in figure $4 \mathrm{c}$ (Jorgensen et al 1987). In general, oxygen non-stoichiometry in the $\mathrm{YBa}_{2} \mathrm{Cu}_{3} \mathrm{O}_{3-\delta}$ system has to be understood in terms of both disorder and structural distortion.

The variation of the superconducting transition temperature of orthorhombic $\mathrm{YBa}_{2} \mathrm{Cu}_{3} \mathrm{O}_{7-\delta}$ with $\delta$ (in the $\delta$-range $0.0-0.5$ ) is most interesting. In figure 5 , the resistivity data of a few members with different $\delta$ values is shown while in figure 6 , the $T_{\mathrm{c}}$ values from the resistivity data are plotted against $\delta$ (Rao et al 1988a). In figure 6, we also show results from the magnetic measurements of Johnston et al (1987). Although the actual $T_{c}$ values vary in the different sets of data (figure 6), we see that the $T_{c}$ is nearly constant around $90 \mathrm{~K}$ at low $\delta(0.0-0.2)$ and drops to a lower value $(\sim 60 \mathrm{~K})$ above $\delta=0.2$ showing a plateau-like behaviour. The $T_{c}$ in the plateau region is similar to that of $\mathrm{La}_{2-x} \mathrm{Ba}_{x}\left(\mathrm{Sr}_{x}\right) \mathrm{CuO}_{4}$ (of the $\mathrm{K}_{2} \mathrm{NiF}_{4}$ structure). Since in this composition range, the $\mathrm{Cu}-\mathrm{O}-\mathrm{Cu}$ chains of $\mathrm{YBa}_{2} \mathrm{Cu}_{3} \mathrm{O}_{7}$ will be depleted, we believe that the $\sim 60 \mathrm{~K}$ plateau is characteristic of superconductivity due to $\mathrm{CuO}_{2}$ 


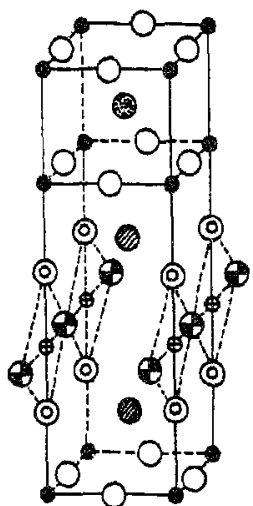

궁

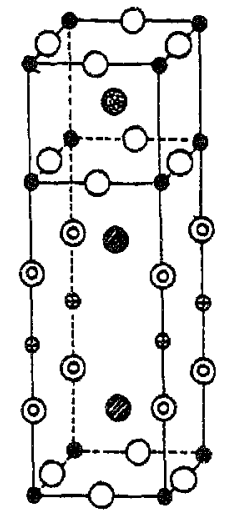

궁

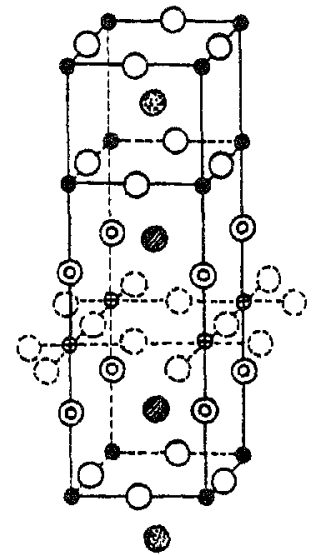

(c)
(2) $Y$

- $\mathrm{Cu}$ in $\mathrm{CuO}_{2}$ layers

- Cuin CuO chains

- Ba

$\mathrm{O}$ Oxygens in $\mathrm{CuO}_{2}$ layers (4)

- Oxygens in CuO chains(1)

- Oxygens in $\mathrm{BaO}$ layers (2)

O Octahedral site oxygen with partial occupancy (disorderd)

(a)

(b)

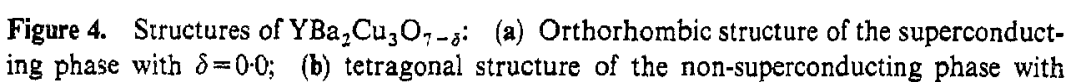
$\delta=1.0$; (c) disordered structure of the tetragonal phase with $\mathrm{CuO}_{6}$ octahedra (where the site occupancy is small).

sheets while the $90 \mathrm{~K} T_{c}$ is characteristic of the sheets in the presence of $\mathrm{Cu}-\mathrm{O}-\mathrm{Cu}$ chains. Figure 6 may therefore be taken to represent a transition from chain-type to sheet-type superconductivity brought about by the change in oxygen stoichiometry.

Several workers have in recent months synthesised derivatives of $\mathrm{YBa}_{2} \mathrm{Cu}_{3} \mathrm{O}_{7-\delta}$ where $\mathrm{Cu}$ is substituted by $\mathrm{Zn}, \mathrm{Ni}, \mathrm{Co}, \mathrm{Fe}$ and such ions or $\mathrm{Ba}$ is substituted by $\mathrm{La}$ and other ions. Such substitution in general lowers $T_{c}$ or destroys the superconductivity, the oxide generally being tetragonal and oxygen-deficient. It should be noted that non-superconducting $\mathrm{YBa}_{2} \mathrm{Cu}_{3} \mathrm{O}_{7-\delta}$ compositions also possess the tetragonal structure. Weakly orthorhombic or nearly tetragonal samples prepared by low-temperature methods are non-superconducting as well. Bulk superconductivity has, however, been recently reported in tetragonal $\mathrm{YBa}_{2}\left(\mathrm{Cu}_{0.96} \mathrm{Co}_{0.4}\right)_{3} \mathrm{O}_{7-\delta}$ (Langen et al 1988).

\section{Other La-Ba-Cu-O and related systems}

The $\mathrm{La}_{3-x} \mathrm{Ba}_{3+x} \mathrm{Cu}_{6} \mathrm{O}_{14+\delta}$ family of oxides were considered to be high $T_{c}$ superconductors (Mitzi et al 1988) even though they did not possess $\mathrm{Cu}-\mathrm{O}$ chains (Er-Rakho et al 1981). It is now known that these oxides are related to the 123 oxides (Segre et al 1987), the relative occupation of the 01/05 sites determining the orthorhombicity. Truly high $T_{c}$ is found in this system only in the orthorhombic structure when $x=1, \delta \approx 0.0$ (Ganapathi et al 1988). All other compositions $(x \neq 1, \delta \neq 0.0)$ are generally tetragonal. In figure 7 , the various rare-earth-containing families of oxides investigated by us for superconductivity are shown.

\section{Bismuth and thallium cuprates}

Two new families of superconducting cuprates with structures related to the 
High-temperature ceramic oxide superconductors

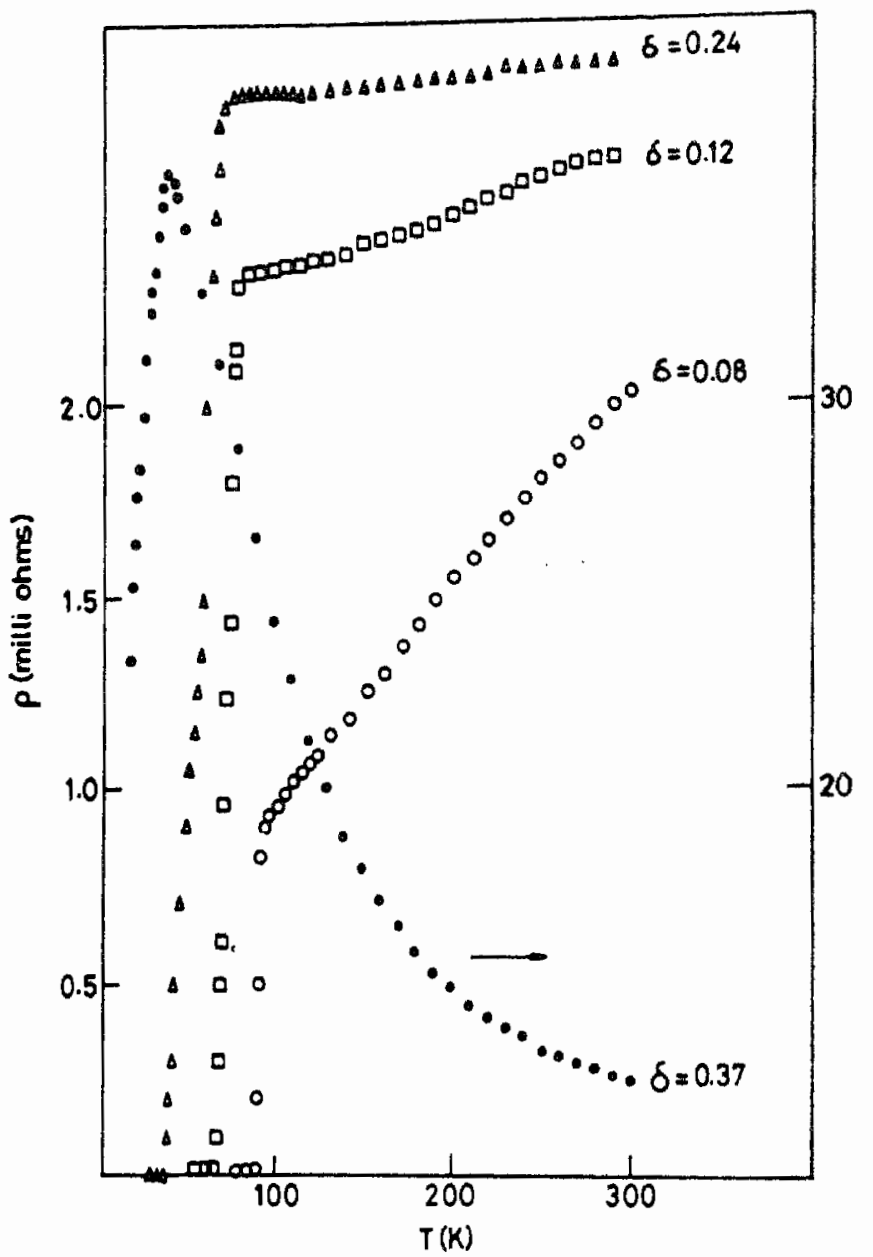

Figure 5. Electrical resistivity behaviour of $\mathrm{YBa}_{2} \mathrm{Cu}_{3} \mathrm{O}_{7-1}$ for different values of $b$ (unpublished results from this laboratory).

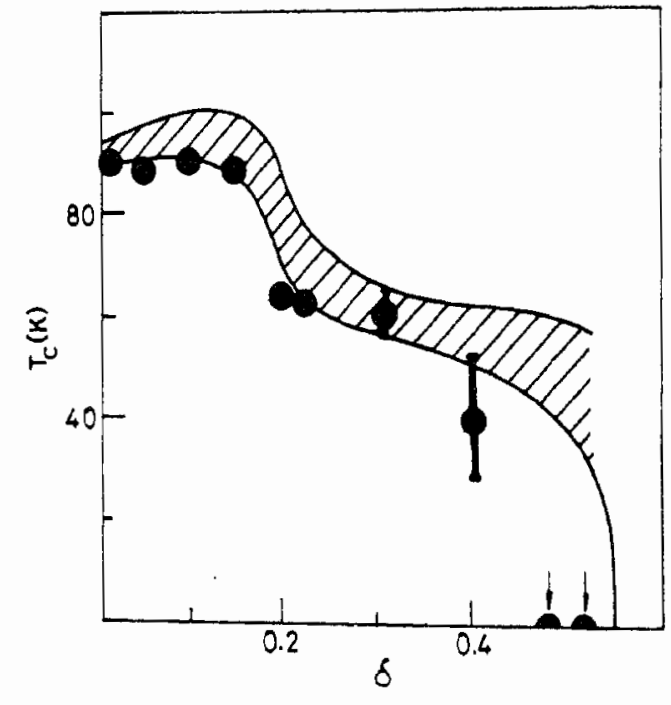

Figure 6. Variation of $T_{r}$ of $\mathrm{YBa}_{2} \mathrm{Cu}_{3} \mathrm{O}_{4.3}$ with $\delta$. Magnetic measurements of Johnston et al (1987) are indicated by the crosshatched region. Our resistivity data are shown by full dark circles (from Rav et al 1988a). 
(21) $\mathrm{La}_{2-x} \mathrm{Ba}_{x}\left(\mathrm{Sr}_{x}\right) \mathrm{CuO}_{4}$

(212) $\mathrm{La}_{2} \mathrm{SrCu}_{2} \mathrm{O}_{6}$

(415) $\mathrm{La}_{4} \mathrm{BaCl} \mathrm{Cu}_{5} \mathrm{O}_{13}$

(336) $\mathrm{La}_{3-x} \mathrm{Ba}_{3+x} \mathrm{Cu}_{6} \mathrm{O}_{14-6}$

(123) $\operatorname{Ln~} \mathrm{Ba}_{2} \mathrm{Cu}_{3} \mathrm{O}_{7-6}$

$(L n=L a, Y, E u, G d, H O, E r$ etc $)$

$(\operatorname{Ln}, \mathrm{Ba})_{n+1} \mathrm{Cu}_{n} \mathrm{O}_{3 n+1}$

(212) $\operatorname{Ln}_{2} \mathrm{BaCu}_{2} \mathrm{O}_{x}$

$\operatorname{Ln} \mathrm{Ba}_{2} \mathrm{Cu}_{2} \mathrm{O}_{x}$

(223) $\mathrm{Ln}_{2} \mathrm{Ba}_{2} \mathrm{Cu}_{3} \mathrm{O}_{x}$
Figure 7. Various families of oxides investigated for superconductivity. SC stands for superconducting. Numbers in parenthesis on the left of each system are the popular designations.

Aurivillius family of oxides with $T_{c}^{\prime}$ 's in the $100 \mathrm{~K}$ region have been discovered. The initial discovery of superconducting bismuth cuprates was by Michel et al (1987) who found $T_{c}$ in the $7-22 \mathrm{~K}$ range in oxides of the type $\mathrm{Bi}_{2} \mathrm{Sr}_{2} \mathrm{Cu}_{2} \mathrm{O}_{7+\delta}$. Maeda et al (1988) then found high $T_{\mathrm{c}}(\sim 100 \mathrm{~K})$ in a Bi-Ca-Sr-Cu-O system. High $T_{\mathrm{c}}$ superconductivity $(\approx 110 \mathrm{~K})$ is exhibited by bismuth cuprates of the type $\mathrm{Bi}_{2}(\mathrm{Ca}, \mathrm{Sr})_{3}$ $\mathrm{Cu}_{2} \mathrm{O}_{8+\delta}$ (Chu et al 1988; Hazen et al 1988; Rao et al 1988; Subramanian et al 1988; Tarascon et al 1988). In figure 8 , we compare the structures of $\mathrm{Bi}_{4} \mathrm{Ti}_{3} \mathrm{O}_{12}$ with that of $\mathrm{Bi}_{2} \mathrm{CaSr}_{7} \mathrm{Cu}_{2} \mathrm{O}_{9}$. In figure 9 , we show the variation of resistivity and $\mathrm{AC}$ susceptibility of a sample to indicate the high $T_{\mathrm{c}}$ behaviour. The bismuth cuprates have less oxygen lability and seem to be more stable. The exact composition of the $110 \mathrm{~K}$ material is more complex than that indicated by the formula $\mathrm{Bi}_{2}(\mathrm{Ca}, \mathrm{Sr})_{3} \mathrm{Cu}_{2} \mathrm{O}_{8+\delta}$.

Thallium cuprates of the Tl-Ba-Cu-O and Tl-Ca-Ba-Cu-O systems show high $T_{c}$ superconductivity with onset in the 100-120 K range (Hazen et al 1988; Ganguli et al 1988; Sheng \& Hermann 1988). In figures 10 and 11, we show the resistivity and susceptibility behaviour of typical members of the Tl-Ca-Ba-Cu-O system. The structure of the 2122 oxide is identical to that of the corresponding bismuth compound, $\mathrm{Bi}_{2} \mathrm{CaSr}_{2} \mathrm{Cu}_{2} \mathrm{O}_{8+8}$. All these oxides of $\mathrm{Bi}$ and $\mathrm{Tl}$ contain $\mathrm{Cu}-\mathrm{O}$ sheets.

Electron microscopic studies of the $\mathrm{Bi}$ and $\mathrm{Tl}$ cuprates show the extensive presence of defects and dislocations just as in the Aurivillius family of oxides. Intergrowths are also present in these systems and they may be responsible for the high $T_{c}$ 's (200$300 \mathrm{~K}$ ) found in some of the samples in this laboratory.

\section{Role of oxygen}

Having established the crucial role of oxygen in the superconductivity of these ceramic oxides, we have further explored the mechanism of superconductivity by means of X-ray photoemission and related studies. Variable-temperature XPS studies 


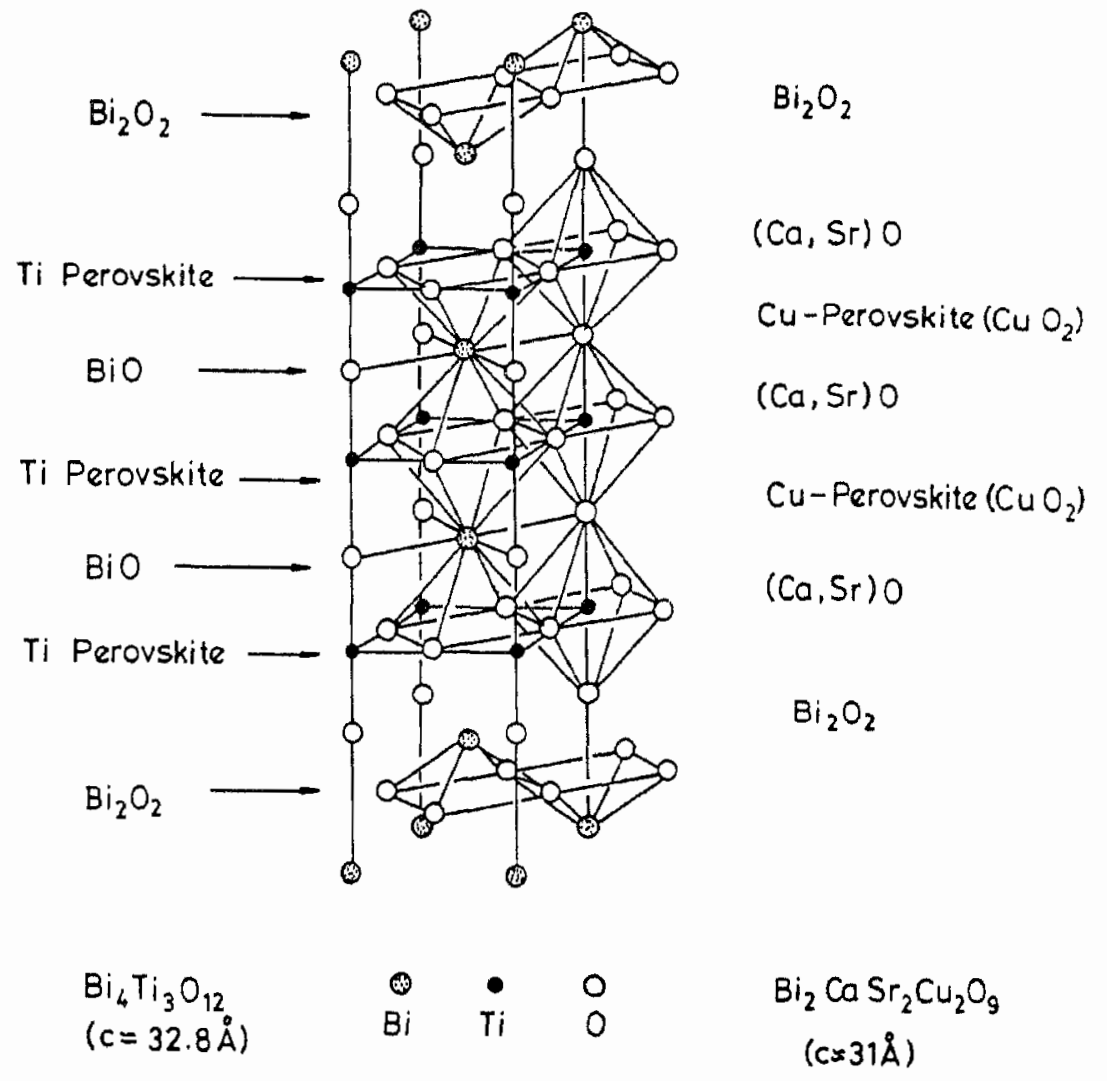

Figure 8. Structure of the orthorhombic Aurivillius phase $\mathrm{Bi}_{4} \mathrm{Ti}_{3} \mathrm{O}_{12}$ and a likely structure of orthorhombic $\mathrm{Bi}_{2} \mathrm{CaSr}_{2} \mathrm{Cu}_{2} \mathrm{O}_{3}$. The recently reported X-ray structure (Subramanian et al 1988) of the latter is identical to this.

on $\mathrm{La}_{1.8} \mathrm{Sr}_{0_{0.2}} \mathrm{CuO}_{4}$ and $\mathrm{YBa}_{2} \mathrm{Cu}_{3} \mathrm{O}_{7}$ in the $\mathrm{O}(\mathrm{ls})$ and $\mathrm{Cu}(2 p)$ regions (Sarma \& $\mathrm{RaO}$ 1987; Sarma et al 1987) show the presence of molecular oxygen species (probably in the peroxide form) with a high $\mathrm{O}(1 \mathrm{~s})$ binding energy of $\sim 533 \mathrm{eV}$, the proportion of which increases with the lowering of temperature (figure 12). The $\mathrm{Cu}(2 p)$ spectrum shows the presence of a well-screened $d^{10}$ state $\left(\mathrm{Cu}^{1+}\right)$ at $933 \mathrm{eV}$ along with a poorly screened $d^{9}$ state $\left(\mathrm{Cu}^{2+}\right)$ at $942 \mathrm{eV}$. The proportion of the $d^{10}$ state increases with the lowering of temperature. There is no evidence for $\mathrm{Cu}^{3+}$ in the $\mathrm{Cu}(2 p)$ or Auger spectra. Auger spectra however clearly show the presence of $\mathrm{Cu}^{1+}$ (figure 13). Based on these findings, it is proposed that holes are present on oxygen rather than on copper in $\mathrm{YBa}_{2} \mathrm{Cu}_{3} \mathrm{O}_{7}$ and $\mathrm{La}_{2-x} \mathrm{Ba}_{x}\left(\mathrm{Sr}_{x}\right) \mathrm{CuO}_{4}$ (note that both are hole conductors). The oxygen holes $\left(\mathrm{O}^{-}\right)$could then dimerize to give peroxide-type species $\left(\mathrm{O}_{2}^{2-}\right)$. Such oxygen holes are found in the $\mathrm{Tl}$ and $\mathrm{Bi}$ cuprates as well. Holes in the $\mathrm{O}(2 p)$ valence bands are favoured by the $\mathrm{Cu}^{1+}\left(d^{10}\right)$ state, just as holes in the $\mathrm{S}(3 p)$ or $\mathrm{Se}(4 p)$ valence bands are generally favoured in $\mathrm{Cu}^{1+}$ chalcogenides.

\section{Some unusual features of the ceramic oxide superconductors}

The most unusual feature of the new sensational high- $T_{c}$ oxides is that they are 

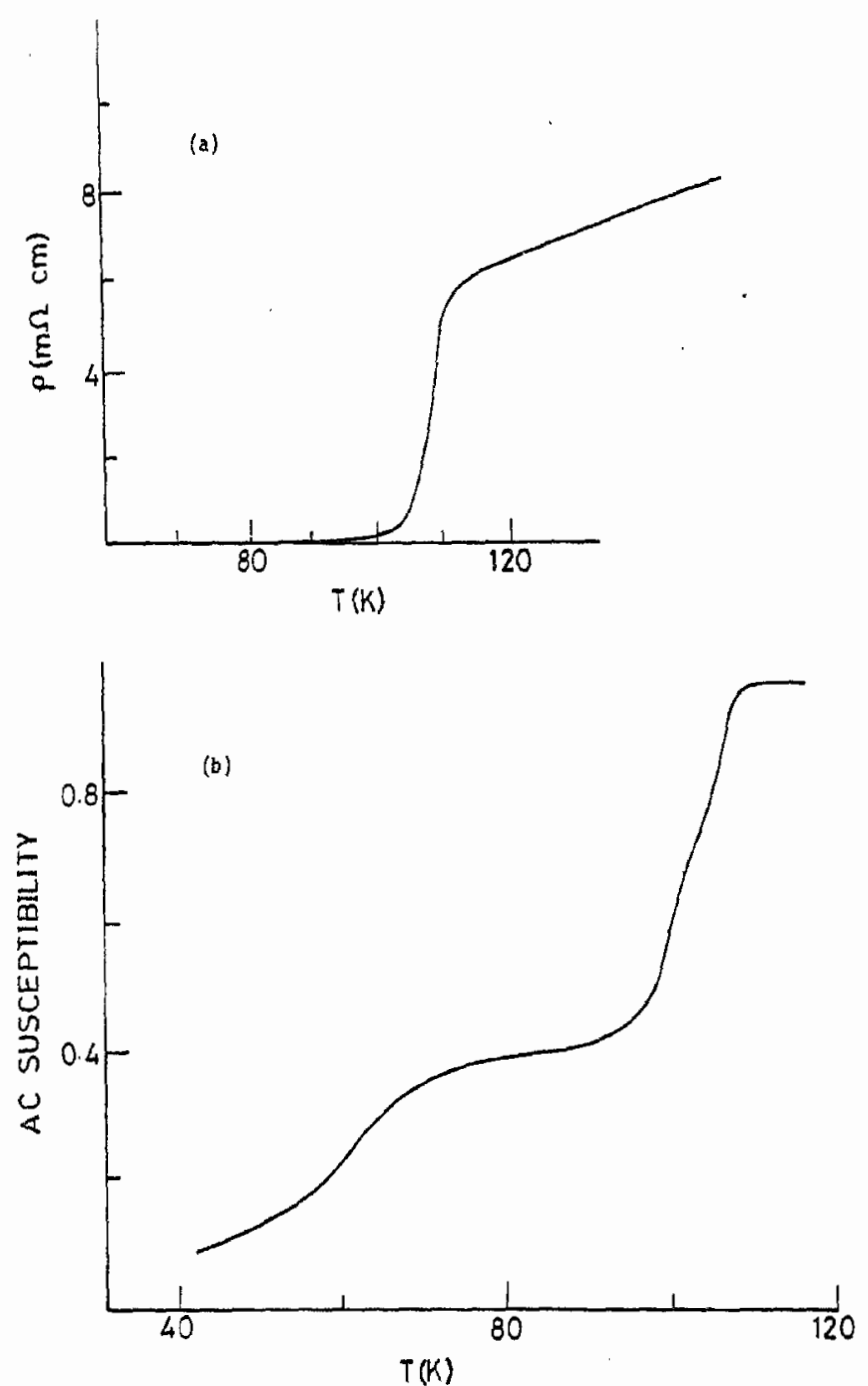

Figure 9. Resistivity and $\mathrm{AC}$ susceptibility data of a sample of $\mathrm{Bi}_{2}\left(\mathrm{Ca}, \mathrm{Sr}_{3} \mathrm{Cu}_{2} \mathrm{O}_{8+\phi}\right.$. (From Tarascon et al 1988.)

ceramic materials (and not metals). As mentioned earlier, in the normal state, they are poor conductors. While $\mathrm{La}_{2}{ }_{-x} \mathrm{Sr}_{x} \mathrm{CuO}_{4}$ seems to exhibit measurable ${ }^{18} \mathrm{O}$ isotope effect, there appears to be essentially no isotope effect in the $\mathrm{YBa}_{2} \mathrm{Cu}_{3} \mathrm{O}_{7-\delta}$ system (Batlogg et al 1987). This means that the traditional BCS* theory is not valid in these oxide superconductors. While electron-phonon interaction could still play an indirect role, the actual nature of the role is not clear at present. The optical gap in $\mathrm{YBa}_{2} \mathrm{Cu}_{3} \mathrm{O}_{7}$ seems to be $\sim 200 \mathrm{~cm}^{-1}$ (Cardona et al 1987; Genzel et al 1987). A highenergy excitonic band $(0.5 \mathrm{eV})$ whose intensity varies with $T_{c}$ seems to be present in $\mathrm{La}_{2-x} \mathrm{Sr}_{x} \mathrm{CuO}_{4}$ and this may be of significance. Such bands need to be further explored. While a large number of papers on theoretical models have appeared in the 


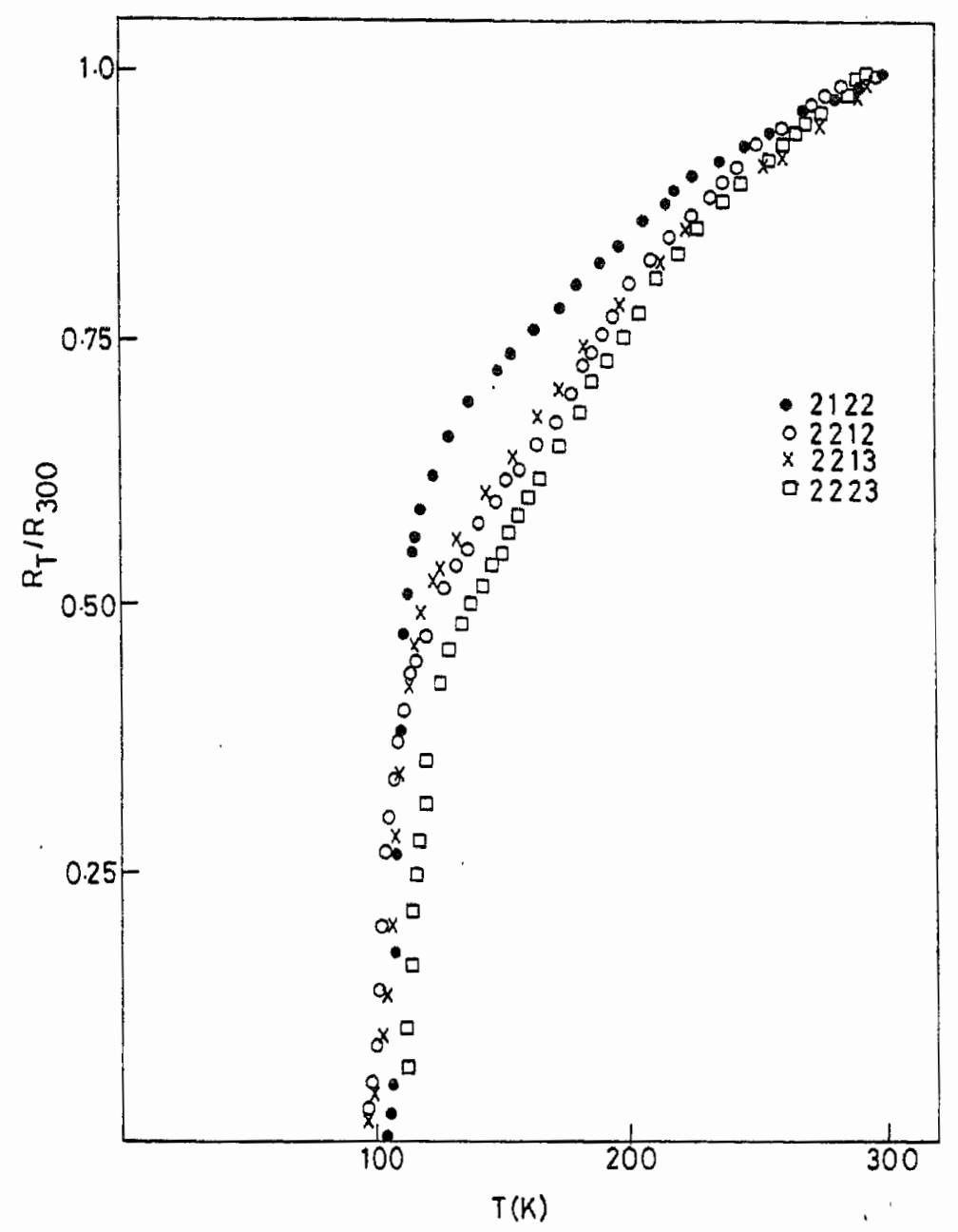

Figure 10. Resistivity behaviour of $2122,2212,2213$ and 2223 members of the T1-Ca-Ba$\mathrm{Cu}-\mathrm{O}$ system (from the author's laboratory). Better samples of 2223 show a $T_{c}$ of $125 \mathrm{~K}$.

literature in the last few months, there is yet no simple model or theory to explain high $T_{c}$ in the oxide superconductors. It seems best to get good experimental data and look for models later. One of the noteworthy features is that $T_{c}$ seems to increase with the number of $\mathrm{Cu}-\mathrm{O}$ layers in the unit cell. The oxygen hole concentration also seems to increase in the same direction as $T_{c}$.

Electron microscopic studies of $\mathrm{YBa}_{2} \mathrm{Cu}_{3} \mathrm{O}_{7}$ show the presence of certain domains (see figure 14) and twin boundaries in addition to other defects (see for example, Rao et al 1987c, 1988a; Subbanna et al 1987). The nature of the domains is causing curiosity. Noting that the coherence length is only a few angstroms, people are wondering about the origin and implications of such domains. Are they due to the co-occurrence of metallic and insulating phases (with different stoichiometry)? If so, what does the observed structure mean? The broad bands or domains (figure 14) found by us sometime ago (Rao et al 1987c), seem to be due to different orientations 


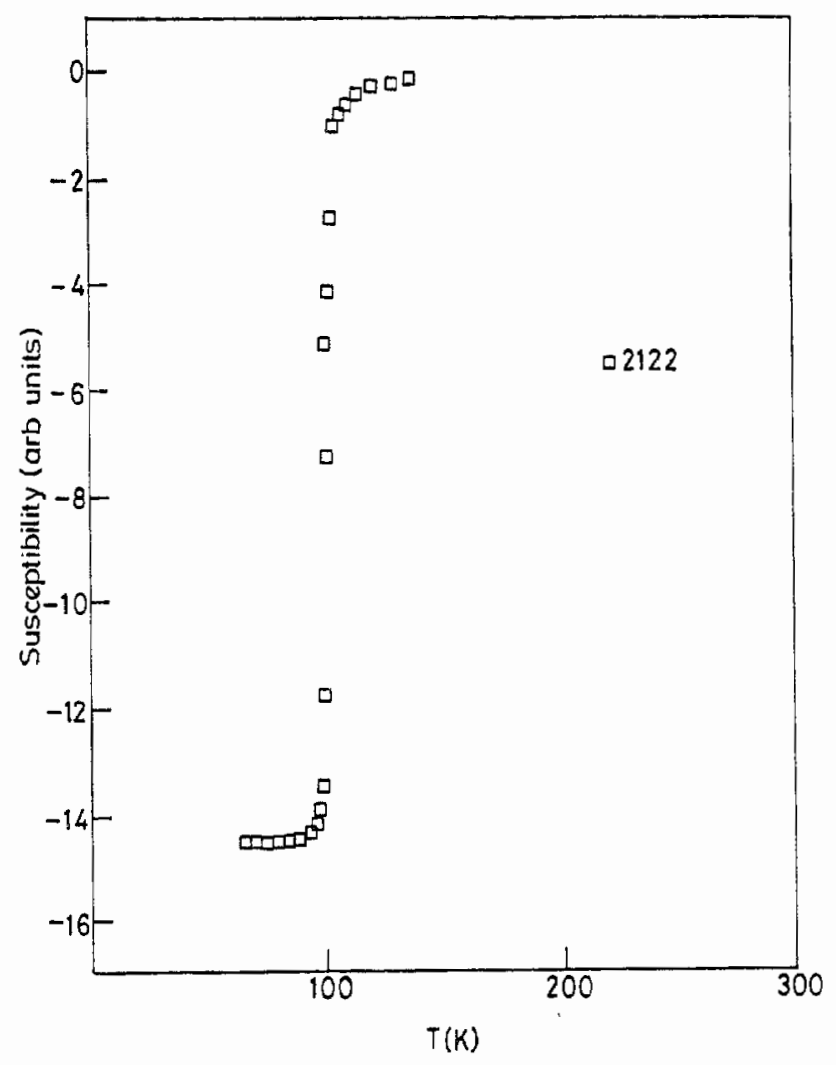

Figure 11. AC susceptibility data of the 2122 member of the Tl-Ca-Ba-Cu-O system (from the author's laboratory).

of the $\left(\mathrm{CuO}_{2}\right)_{\infty}$ units (Rao et al 1988a). Such macroscopic features may be responsible for the unstable very high $T_{c}(\sim 300 \mathrm{~K})$ behaviour of some oxides.

An interesting property of $\mathrm{YBa}_{2} \mathrm{Cu}_{3} \mathrm{O}_{7}$ in the superconducting state is that it absorbs electromagnetic radiation over a wide range of frequencies from a few $\mathrm{MHz}$ to a few $\mathrm{GHz}$ (Bhat et al 1987). The absorption is extremely sensitive to temperature, particle size and the magnetic field and crucially depends on the presence of ambient oxygen. It is suggested that Josephson junctions formed by oxygen and the superconducting grains may be responsible for this effect.

\section{Material parameters and applications}

Since these new oxide superconductors are ceramic materials, there are inherent problems in obtaining them in the desired shape and form. However, there has already been considerable success in making wires, tapes and films. During the processing of these materials, there is a tendency to lose the labile oxygen which renders them non-superconducting; this can be solved by reheating the processed material in oxygen or by proper insulation in the initial stage itself. Another difficulty with these oxide ceramics is their chemical instability. Success in technological 


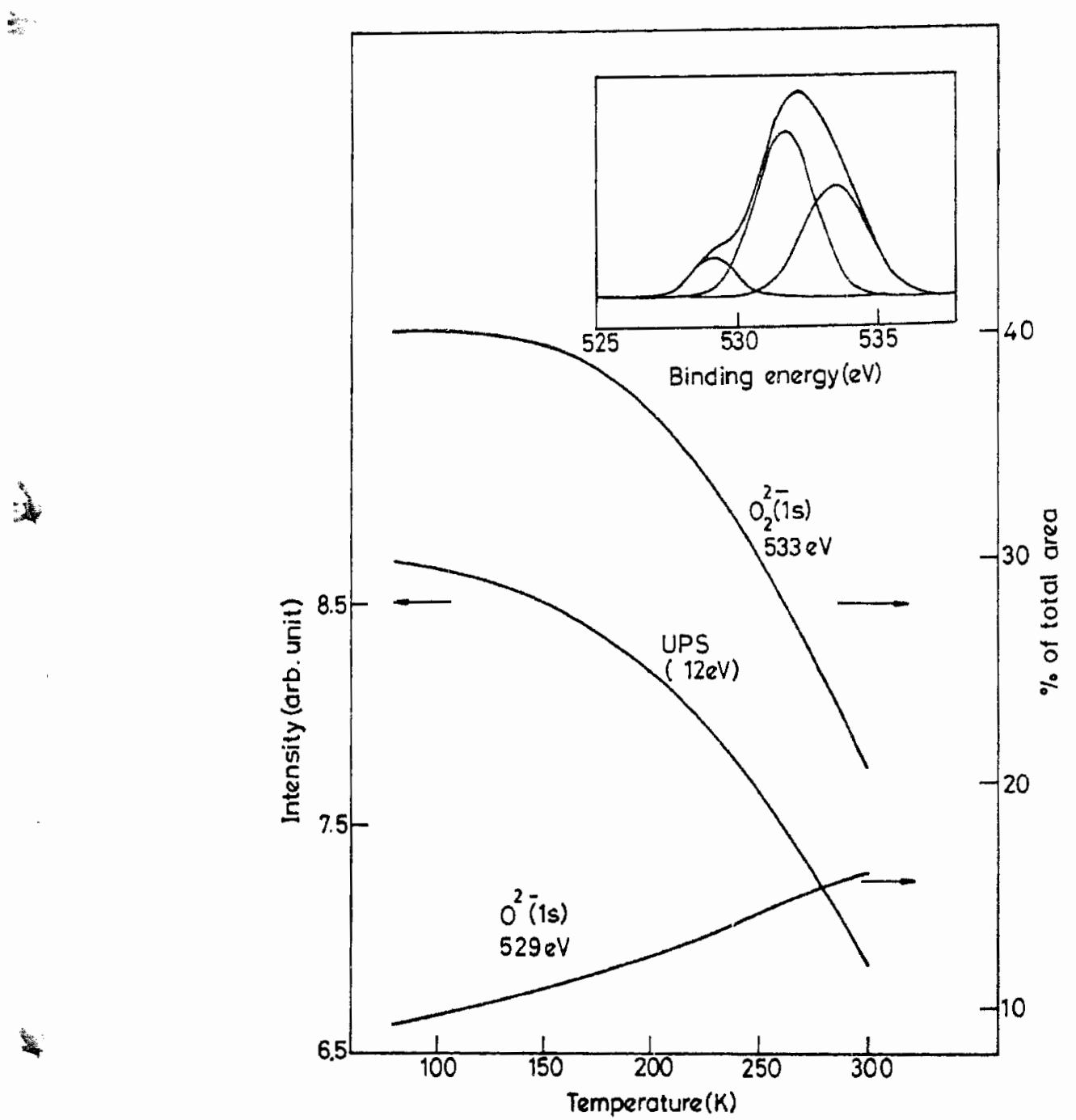

Figure 12. Temperature-variation of $\mathrm{O}(1 s)$ peak intensity due to $\mathrm{O}^{2-}$ and $\mathrm{O}_{2}^{2-}$ species (at 529 and $533 \mathrm{eV}$ respectively) in $\mathrm{YBa}_{2} \mathrm{Cu}_{3} \mathrm{O}_{7}$. Temperature-variation of the intensity of $\mathrm{He}$ II spectrum at $12 \mathrm{eV}$ is also shown. Inset shows the $\mathrm{O}(1 \mathrm{~s})$ signal at $80 \mathrm{~K}$ as consisting of three Gaussians peaking at 529,531 and $533 \mathrm{eV}$, the one at $531 \mathrm{eV}$ being due to $\mathrm{O}^{-}$or impurity species (from Rao et al 1987a).

applications will depend on several factors (material parameters, cost etc.) as shown below.

Since $\mathrm{YBa}_{2} \mathrm{Cu}_{3} \mathrm{O}_{7}$ is superconducting well above the liquid nitrogen temperature, it holds much promise. We shall briefly examine the material parameters of this ceramic oxide. Electronic properties of this oxide are anistropic (just as the structure). Some of its important properties are as follows (Malozemoff et al 1987):

1. It is a Type II superconductor.

2. Hall carrier density: $4 \times 10^{21} \mathrm{~cm}^{-3}$ (for a material of resistivity $\sim 400 \mu \Omega \mathrm{cm}$ just above the $T_{c}$ ). 


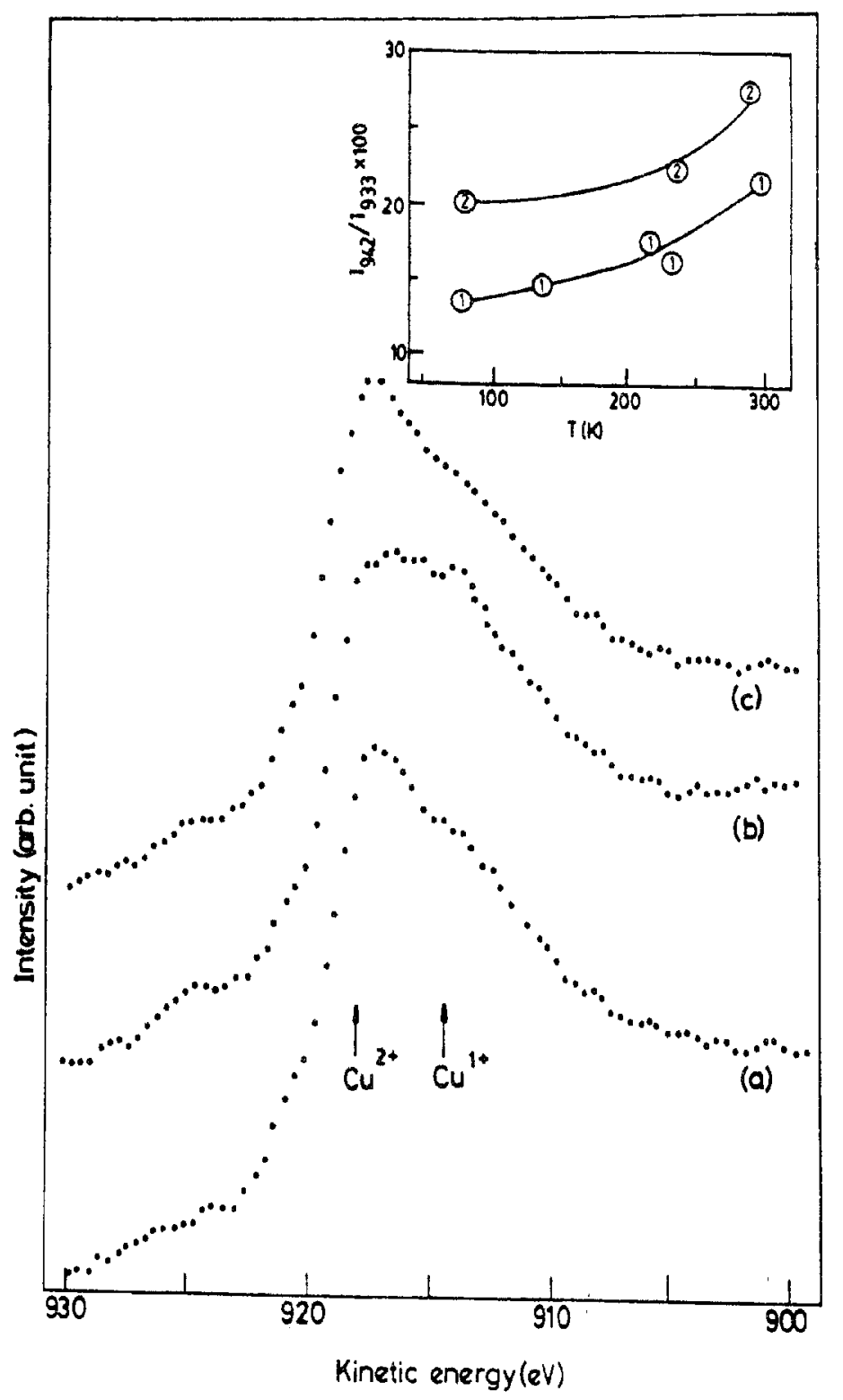

Figure 13. $\mathrm{Cu}\left(\mathrm{L}_{3} \mathrm{VV}\right)$ Auger spectrum of $\mathrm{YBa}_{2} \mathrm{Cu}_{3} \mathrm{O}_{7}$ at diferent temperatures. In the inset, the temperature variation of the intensity of the $942 \mathrm{eV}$ feature relative to that of the $933 \mathrm{eV}$ feature in the $\mathrm{Cu}\left(2 p_{3 / 2}\right)$ spectrum is shown. 1 and 2 refer to independent sets of measurements (from Sarma \& Rao 1987).

3. $\mathrm{d} H_{c 2} / \mathrm{d} T=2 T / \mathrm{K}$,

BCS coherence length $\approx 1.4 \mathrm{~nm}$,

London penetration depth $\approx 200 \mathrm{~nm}$,

Mean free path $\approx 1.2 \mathrm{~nm}$.

4. $H_{\mathrm{c}}(0) \approx 1 T$.

5. $H_{\mathrm{c} 2}(\mathrm{O}) \approx 120 T$. 


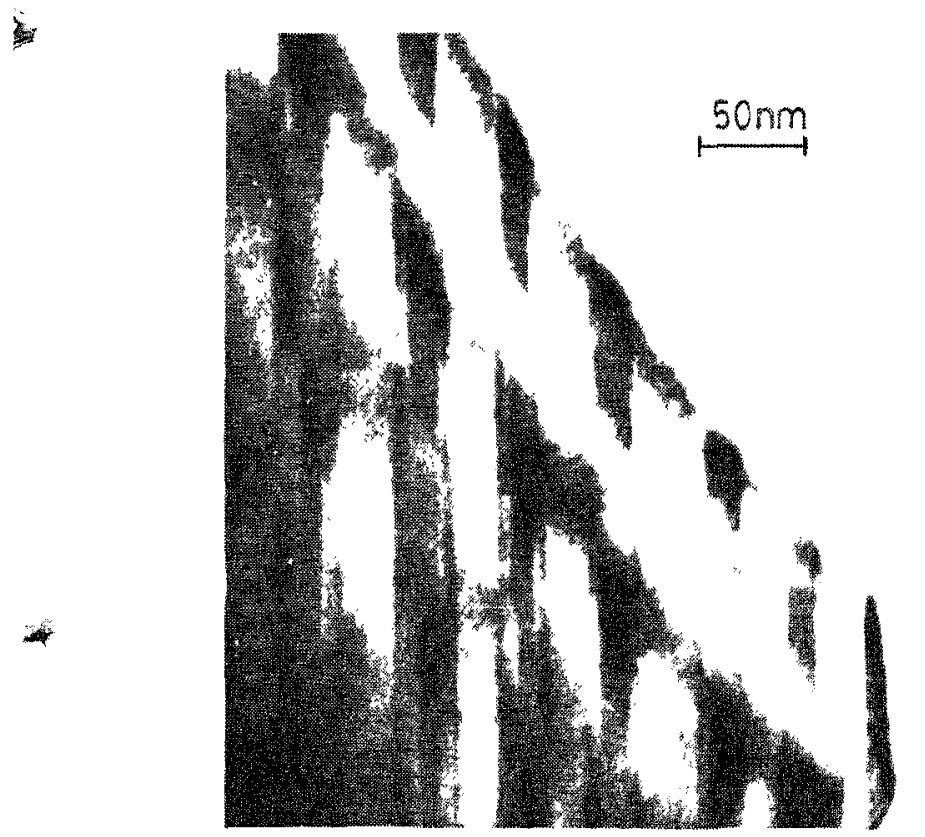

Figure 14. Bands (somains) in electron micrographs of $\mathrm{YBa}_{2} \mathrm{C}_{3} \mathrm{O}$, (I'rom RaO at al $1987 \mathrm{c}$.

6. Critical current density: in ceramic samples $\sim 10^{3} \mathrm{~A} / \mathrm{cm}^{2}$ at $77 \mathrm{~K}$, in films (on $\mathrm{SrTiO}_{3}$ ) $\sim 10^{5} \mathrm{~A} / \mathrm{cm}^{2}$ at $77 \mathrm{~K}$, in crystals and films $\sim 10^{6} \mathrm{~A} / \mathrm{cm}^{2}$ at $4.2 \mathrm{~K}$.

Depairing current density: $10^{7}-10^{8} \mathrm{~A} / \mathrm{cm}^{2}$ (estimated).

The big market for superconducting materials is in magnetic resonance imaging for medical applications. The other magnetic applications with commercial implications are in high energy physics, high field magnets for scientific investigations and magnetic separation. Magnetic confinement of plasma (fusion), levitating transportation vehicles and magnetohydrodynamics are some of the applications where commercialization will not be in the near future. In all these applications the factors that will determine the use of the new ceramics are cost advantages and material performance characteristics. The most crucial material parameter is the critical current density; it is necessary to obtain high values in large scale production of the ceramic material. Even if this becomes possible, the material cost per ampere metre will be crucial. The biggest factor is the refrigeration cost. At present, the cost of $\mathrm{YBa}_{2} \mathrm{Cu}_{3} \mathrm{O}_{7}$ (for use at $77 \mathrm{~K}$ ) seems to be much higher than traditional superconductors. It is however hopeful that the usable current density of $\mathrm{YBa}_{2} \mathrm{Cu}_{3} \mathrm{O}_{7}$ will soon be higher than $\mathrm{Nb}_{3} \mathrm{Sn}$ for high-field applications. In the mean time, problems of fabrication and chemical stability have to be sorted out.

Use of these superconducting oxides for power transmission lines is a possibility. While the cost factor (of the material and for refrigeration) has to be carefully examined, there is every hope that $\mathrm{YBa}_{2} \mathrm{Cu}_{3} \mathrm{O}_{7}$ at $77 \mathrm{~K}$ can be used profitably in the long run at least for underground lines.

The most immediate application that seems realistic is the use of $\mathrm{YBa}_{2} \mathrm{Cu}_{3} \mathrm{O}_{7}$ as interconnects in computers. Other electronic applications are in mm-wave detection, high-speed digital and analog signal processing and digital Josephson technology. Electronic instruments utilizing superconductivity such as sensitive SQUID magneto- 
meters, high speed samplers and voltage standards based on Josephson effects as well as non-Josephson devices such as superconducting bolometers and sis mixers are areas where success is likely. Transistor-like devices compatible with oxide superconductors need to be explored vigorously.

The new bismuth cuprates are promising since they are more stable chemically and with respect to oxygen stoichiometry; good films have already been made. Thallium cuprates may not be used as they are poisonous.

\section{Concluding remarks}

The tremendous possibilities for wide application of $\mathrm{YBa}_{2} \mathrm{Cu}_{3} \mathrm{O}_{7}$ and other high $T_{c}$ ceramic oxides make this area of research most exciting. Clearly, the hightemperature ceramic oxide superconductors constitute the most sensational discovery since the transistor; it has given a great boost to research in solid state science and engineering. There is no doubt that within a short time frame, some commercial applications will become a reality even with existing materials. The future offers unlimited vistas and opportunities in electromagnetic technology as well as in oxide ceramics research. Synthesis of materials with $T_{c}$ 's close to room temperature or higher is no longer a remote possibility.

The author thanks the Department of Science and Technology, Government of India, and the University Grants Commission for support of this research. He also expresses his deep sense of gratitude to his collaborators for their enthusiastic participation in the research activities related to oxide superconductors.

\section{References}

Batlogg B, Cava R J, Jayaraman A, van Dover R B, Kouroukis G A, Sunshine S, Murphy D W, Rupp L W, Chen H S, White A, Short K T, Mujsce A M, Rietman E A 1987 Phys. Rev. Lett. 58: 2333-2336

Bednorz 3 G, Mueller K A. 1986 Z. Phys. B64: 189-193

Beille J, Cabanel R, Chaillout C, Chevalier B, Demazeau G, Deslandes F, Etourneau J, Le Jay P, Michel C, Provost J, Raveau B, Sulpice A, Tholence J, Tournier R 1987 C.R. Acad. Sci. Paris 18: 304-308 Bhat S V, Ganguly P, Ramakrishnan T V, Rao C N R 1987 J. Phys. C, Solid State 20: L559-563

Birgeneau R J, Chen C Y, Gabbe D R, Jenssen H P, Kastner M A, Peters C J, Picone P J, Thio T, Thurston T R, Tuller H L 1987 (to be published)

Bordet P, Chaillot C, Capponi J J, Chenavas J, Marezio M 1987 Nature (London) 327: 687-689

Cardona M, Genzel L, Liu R, Wittlin A, Mattausch H, Garcia-Alvarado F, Garcia-Gonzalez E 1987 Solid State Commun. 64: 727-732

Cava R S, van Dover R B, Batlogg B, Reitman E A 1987 Phys. Rev. Lett. 58: 408-410

Chu C W, Bechtold J, Gao L, Hor P H, Huang Z J, Meng R L, Sun Y Y, Wang Y Q, Xue Y Y 1988 Phys. Rev. Lett, 60: 941-943

Chu C W, Hor P H, Meng R L, Gao L, Huang Z J, Wang Y Q 1987 Phys. Rev. Lett. 58: 405-407

David W I F, Harrison W T A, Gunn J M F, Moze O, Soper A K, Day P, Jorgensen J D, Beno M A, Capone D W, Hinks D G, Schuller I K, Soderholm L, Segre C U, Zhang K, Grace J D 1987 Nature (London) 327: 310-312

Day P, Resseinsky M, Prassides K, David W I F, Moze O, Siper A 1987 J. Phys. C, Solid State. 20: L429-434

Er-Rakho L, Michel C, Provost J, Raveau B 1981 J. Solid State Chem. 37: 151-156

Ganapathi L, Ganguli A K, Mohan Ram R A, Rao C N R 1988 J. Solid State Chem. 73: (in print)

Ganguli A K, Subbanna G N, Umarji A M, Bhat S V, Rao C N R 1988 Pramana-J. Phys. 30: L483-L490

Ganguly P, Rao C N R 1984 J. Solid State Chem. 53: 193-216

Ganguly P, Mohan Ram R A. Sreedhar K, Rao C N R 1987a Solid State Commun. 62: 807-809 
High-temperature ceramic uxide' supterconductors

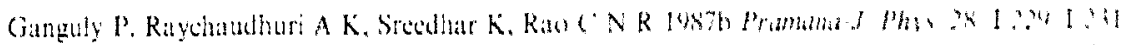

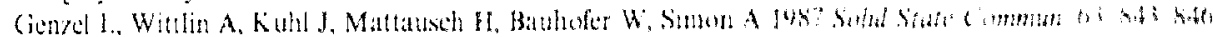

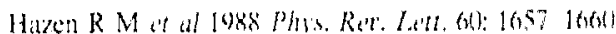

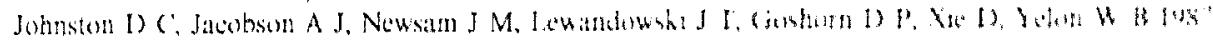

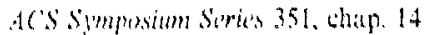

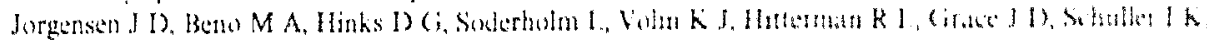

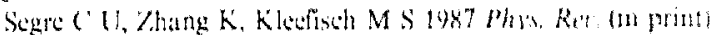

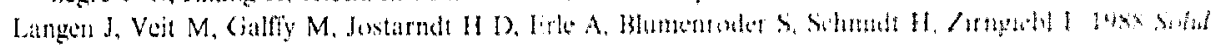
Situte Commun 65: 973 476

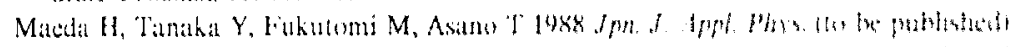

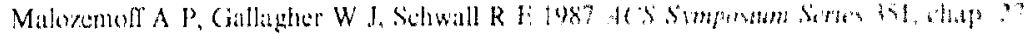

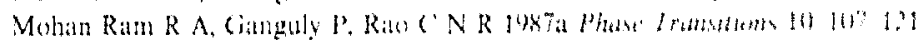

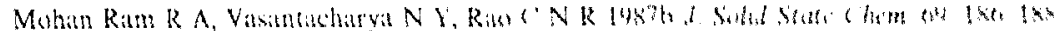

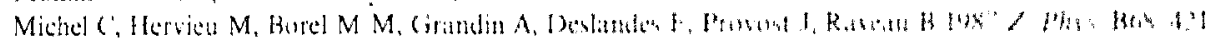

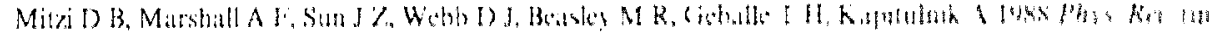
print)

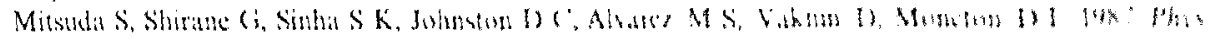

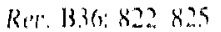

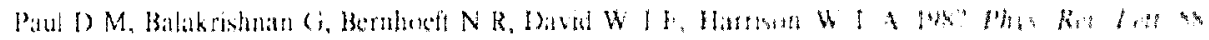
19761978

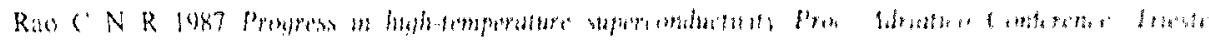

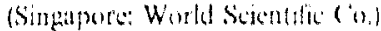

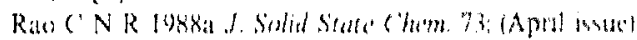

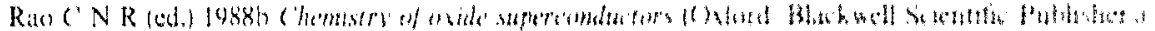

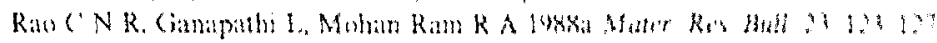

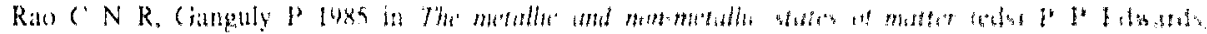
('NR Rato (londun: laylur and lrambers!

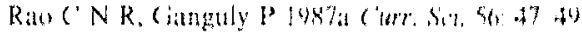

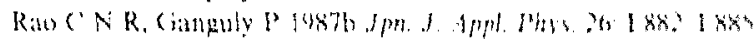

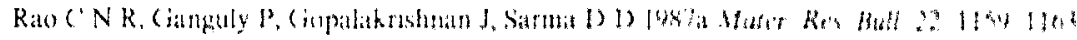

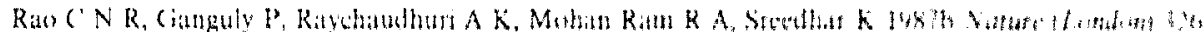
$856 \times 5.57$

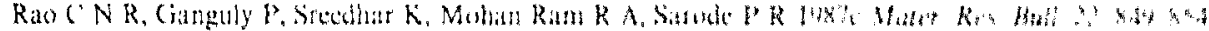

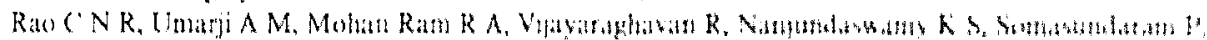

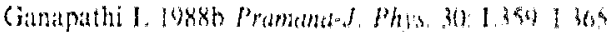

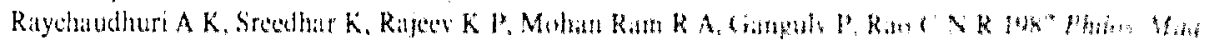
L.11. 5(2:20).34

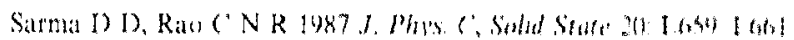

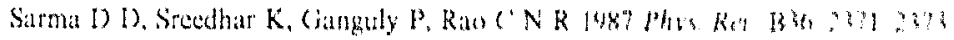

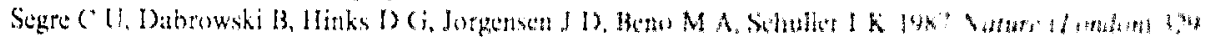
227229

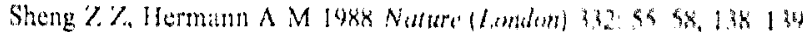

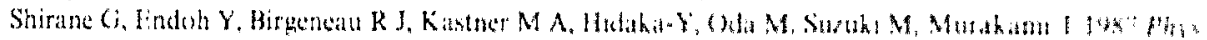
Ron, latt. 59: 1613 1616

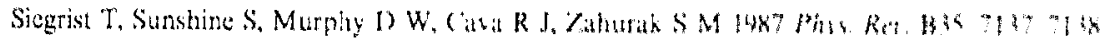

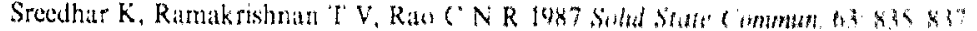

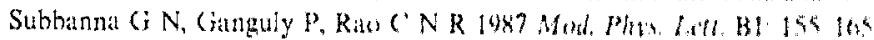

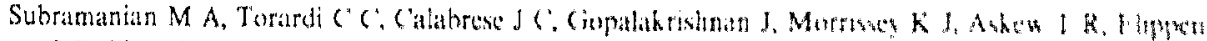
R B, Chowdhry U, Sleight A W 19k8 Sitome 23, 1015 1018

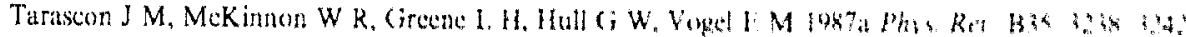

Tarascon J $M$ of al 19876 'res'. MRS' Meeting, Anaheim

Tarascon J M at al $198 \mathrm{~g}$ (t) be published)

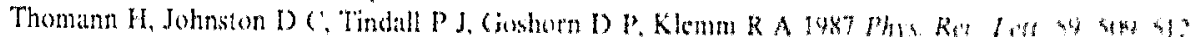

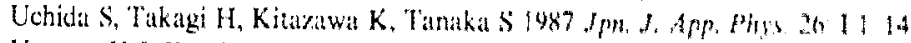

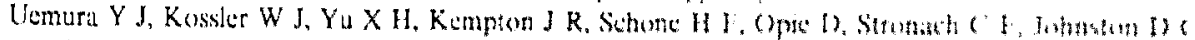
Alvarez M S, Goshom D P 1987 (10) be published)

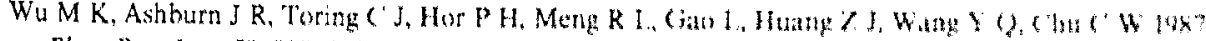
Phys. Rev. Lett. $58: 9089(0)$

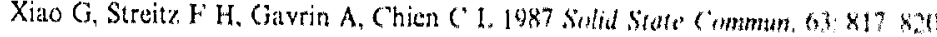

